\title{
Article \\ Transcriptional Regulatory Networks Associate with Early Stages of Potato Virus X Infection of Solanum tuberosum
}

\author{
Venura Herath ${ }^{1,2}$ (D) and Jeanmarie Verchot ${ }^{1, *(1)}$ \\ 1 Department of Plant Pathology and Microbiology, Texas A\&M University, College Station, TX 77802, USA; \\ venura@agri.pdn.ac.lk \\ 2 Department of Agriculture Biology, Faculty of Agriculture, University of Peradeniya, \\ Peradeniya 20400, Sri Lanka \\ * Correspondence: jm.verchot@tamu.edu; Tel.: +1-979-286-1788
}

check for updates

Citation: Herath, V.; Verchot, J.

Transcriptional Regulatory Networks Associate with Early Stages of Potato Virus X Infection of Solanum

tuberosum. Int. J. Mol. Sci. 2021, 22, 2837. https://doi.org/10.3390/ ijms22062837

Academic Editor: Frank M. You

Received: 12 February 2021

Accepted: 9 March 2021

Published: 11 March 2021

Publisher's Note: MDPI stays neutral with regard to jurisdictional claims in published maps and institutional affiliations.

Copyright: (c) 2021 by the authors. Licensee MDPI, Basel, Switzerland. This article is an open access article distributed under the terms and conditions of the Creative Commons Attribution (CC BY) license (https:// creativecommons.org/licenses/by/ $4.0 /)$.

\begin{abstract}
Potato virus X (PVX) belongs to genus Potexvirus. This study characterizes the cellular transcriptome responses to PVX infection in Russet potato at 2 and 3 days post infection (dpi). Among the 1242 differentially expressed genes (DEGs), 268 genes were upregulated, and 37 genes were downregulated at 2 dpi while 677 genes were upregulated, and 265 genes were downregulated at 3 dpi. DEGs related to signal transduction, stress response, and redox processes. Key stress related transcription factors were identified. Twenty-five pathogen resistance gene analogs linked to effector triggered immunity or pathogen-associated molecular pattern (PAMP)-triggered immunity were identified. Comparative analysis with Arabidopsis unfolded protein response (UPR) induced DEGs revealed genes associated with UPR and plasmodesmata transport that are likely needed to establish infection. In conclusion, this study provides an insight on major transcriptional regulatory networked involved in early response to PVX infection and establishment.
\end{abstract}

Keywords: PVX; gene expression regulation; RNA-seq; Solanum tuberosum; potato virology; virus movement; host-pathogen interactions; antiviral defense; potexvirus

\section{Introduction}

Potato virus $X(\mathrm{PVX})$ is a positive-strand RNA virus that infects potatoes, although primarily studied in model hosts, Nicotiana benthamiana and Arabidopsis. In N. benthamiana leaves inoculated with the PVX infectious clone containing the green fluorescent protein (GFP) gene [1-3], the primary infection occurs in foci that expand radially by cell-to-cell movement in all directions. PVX-GFP fluorescent foci typically appear at a macroscopic level within the first 2 or 3 days post-inoculation (dpi). Around $5 \mathrm{dpi}$, the virus typically reaches nearby veins and begins to load into the phloem for transport out of the inoculated leaf to unload in the upper leaves [4-7]. The time-frame for virus entry into the vascular system is contingent upon the density of vascular patterning and leaf dimensions $[8,9]$. After PVX-GFP enters the phloem, it is transported to multiple distal regions of the plant to establish systemic infection.

Within the first few hours or days of infection, viruses enact critical steps to establish themselves in the host cell and initiate replication. PVX engages chaperones and other proteins into replication complexes [10-12] and alters cellular membranes to build scaffolds. PVX also affects the cell's program to protect against host defenses and suppresses posttranscriptional gene silencing [13]. Recent evidence suggests that virus effector-proteins target regulatory nodes of cellular pathways to create an environment that favors infection $[14,15]$. For example, viral silencing suppressor proteins interfere with different steps of the RNAi machinery [16]. Small membrane-binding proteins embedded in the endoplasmic reticulum manipulate the unfolded protein response machinery [17]. Other targets include autophagy, RNA granules, vesicle trafficking, lipid metabolism, and phytohormones [18]. Moreover, some cellular pathways are not globally conserved, such as those 
between monocot and dicots, or the defense-related steroidal glycoalkaloids (SGAs) in Solanum species $[19,20]$. Therefore, it is necessary to investigate the cellular responses to virus infection in agronomic hosts if we ever expect to use science to deploy sensible crop improvement strategies.

During the past decade, most "omic" approaches to uncover the transcriptional and metabolic responses to plant virus infection used systemically infected model hosts, although a few studies used microarray or RNA-seq technologies to report transcription, small interfering RNA, or micro RNA profiles in potato during infection with potato virus $Y$, or potato spindle tuber viroid [21-24]. Few studies investigate the early responses to virus infection model or agronomic hosts, and there are no studies until now using PVX in potato. This study was undertaken to investigate the cellular pathways in S. tuberosum that are potential targets for PVX exploitation during the radial expansion of primary infection foci. For this, we analyzed gene expression changes at 2 and 3 dpi with PVX by RNA-Seq. This next-generation technology took advantage of the recently updated version 6.1 genome sequence of DM1-3 516 R44, a doubled monoploid clone of S. tuberosum, representing a high-quality annotation dataset [25]. The data presented in this study identified a small set of genes that likely play important roles in establishing virus infection.

\section{Results}

\subsection{Inoculation of Potato Plants with PVX-GFP and Evaluation of Virus Infection}

Potato plants were inoculated with plant sap containing PVX-GFP virions by rub inoculation prior to RNAseq analysis. To standardize the virus inoculum for application to the S. tuberosum (cv Russet Norkotah) leaves, the Holmes' assay was carried out using Chenopodium quinoa plants, a known local lesion host for PVX. The Holme's assay is based on the premise that the virus titer is proportional to the dilution of the extracts that can be visualized and counted using a local lesion host. This Holmes' local lesion assay is a standard approach to reporting the proportion of virus in a volume of extract and for comparing infectivity of different inocula sources [26]. C. quinoa and potato plants were maintained in a growth room at a constant temperature of $23{ }^{\circ} \mathrm{C}$ and $16 \mathrm{~h} \mathrm{light}$. A dilution series of soluble leaf homogenate was prepared from $N$. benthamiana plant that was systemically infected with PVX-GFP and then rub-inoculated onto Chenopodium quinoa leaves. Lesions first appear as chlorotic spots and expand to necrotic sports surrounded by green rings (Figure S1A,B). We selected an inoculum of $20 \mu \mathrm{L}$ of a 1:5 $(w / v)$ dilution in phosphate buffer that produced an average of 45 foci per leaf $(n=5)$ [27] to use in subsequent potato experiments (Figure S1C). Next, this inoculum was applied to potato leaves and then PVX-GFP fluorescence was viewed using a stereo fluorescent microscope and $20 \times$ objective. At 2 and $3 \mathrm{dpi}$ and there was an average of 27 infection foci per inoculated leaf ( $n=4$; Figure S1D,E). Using the Holme's assay combined with viewing GFP was important to monitor the titer of PVX-GFP inoculum and distribution of infection foci across leaves for determining the sampling time. This was needed to satisfy a model of virus fitness proposed by Rodrigo et al. (2014) which implies that the appropriate abundance of primary infection foci during this period of 2-3 days represents conditions that support robust replication and cell-to-cell movement toward establishing systemic infection [28]. Infected leaves were harvested and RNA was extracted. PVX-GFP infection was further confirmed RT-PCR.

\subsection{A Genome-Wide Analysis of Differentially Expressed Genes (DEGs) in Potato Inoculated with PVX-GFP}

An RNA-seq study was conducted using the BGISEQ-500 platform to capture the transcriptome changes occurring during the early stages of infection which likely occur to support virus replication and cell-to-cell movement. We inoculated nine single largest leaflets of compound potato leaves. Three leaflets were pooled and RNA was extracted at 2 and 3 dpi. Transcription profiles were determined for three replicate samples at 2 and 3 dpi. We obtained 453.39 million raw and 406.91 million clean read pairs mapping to the 
reference genome using HISAT2 software (Table S1). A total of 336.97 million read pairs were uniquely mapped to the reference genome representing approximately $83 \%$ of the clean reads. The total alignment rate including unique and multi-mapped reads with the reference genome was $89.75 \%$ indicating this is a quality dataset.

The total number of differentially expressed genes (DEGs) are represented in volcano plots with the upregulated transcripts identified in red and, the downregulated transcripts in blue (Figure 1A). A Venn diagram of transcripts (Figure 1B) identifies a total of 306 DEGs at $2 \mathrm{dpi}$, which is the sum of 268 upregulated and 37 downregulated genes which are listed in Tables S2 and S3. At 3dpi, there were 942 DEGs, including 677 upregulated and 265 downregulated genes. At 2 and 3 dpi, 73 similar genes were upregulated, and seven similar genes were downregulated. Four genes were downregulated at 2 dpi but upregulated at $3 \mathrm{dpi}$. Thirty-seven genes were upregulated at $2 \mathrm{dpi}$ but downregulated at $3 \mathrm{dpi}$ (Figure 1B, Tables S2 and S3).
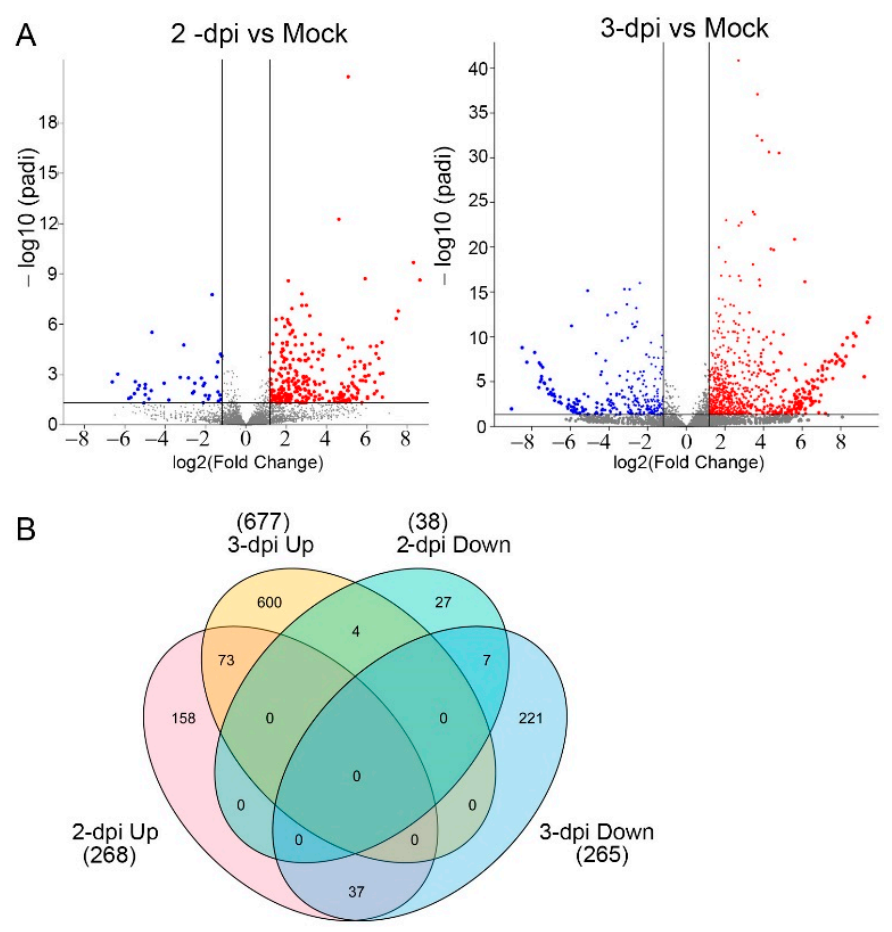

Figure 1. Differentially expressed number of genes (DEGs). (A) Volcano plots show the significantly upregulated genes in blue and downregulated genes in red $(p<0.05)$. (B) Venn diagram highlighting unique and common DEGs in PVX-GFP infected leaves at 2 and 3 dpi across multiple comparisons using a $-\log 10$ adjusted $p$-value.

Gene Ontology (GO) describes gene products in the categories of biological process, molecular function, and cellular component. To understand the complex expression patterns portrayed in Figure 1B, we performed GO enrichment analysis to cluster proteins of similar functions within the DEG datasets (Figure 2) [29]. Regarding the upregulated genes, we found a GO IDs associating with biological processes at 2 dpi included oxidative stress processes which made up $22 \%$ and cellular protein modification which was $20 \%$ of sequences (Figure 2A). Two similar terms which might be considered together are "response to stress" and "cellular response to stimuli" which corresponded to $17 \%$ and $3 \%$ of gene sequences. Response to transcription and phosphorylation were each $15 \%$ and the transport was $8 \%$. At $3 \mathrm{dpi}$, regulation of transcription and oxidative stress each comprised $30 \%$ of sequences. Transmembrane transport was $22 \%$ and protein metabolic processes represented $5 \%$ of sequences (Figure $2 \mathrm{~A}$ ). Regarding cellular component, integral membrane proteins comprised $42 \%$ of sequences at 2 dpi and $59 \%$ at 3 dpi. Cytoplasmic factors represented $25 \%$ and $24 \%$ of sequences at 2 and 3 dpi, respectively (Figure $2 \mathrm{~B}$ ). Genes 
associated with the nucleus representing $23 \%$ of sequences at $2 \mathrm{dpi}$ and $18 \%$ of sequences at 3 dpi. Genes associated with the plasma membrane represented $10 \%$ of sequences at $2 \mathrm{dpi}$ (Figure 2B). At 2 dpi, four GO terms for molecular functions were identified: metal ion binding, DNA binding, heme-binding/peroxidase activity, and kinase activity (Figure 2C). At $3 \mathrm{dpi}$, there are two GO categories of molecular functions: metal ion binding and DNA binding. Metal ion binding points to potential enzymatic activities, kinase activities suggest signal transduction cascades, and DNA binding points to transcriptional regulation.

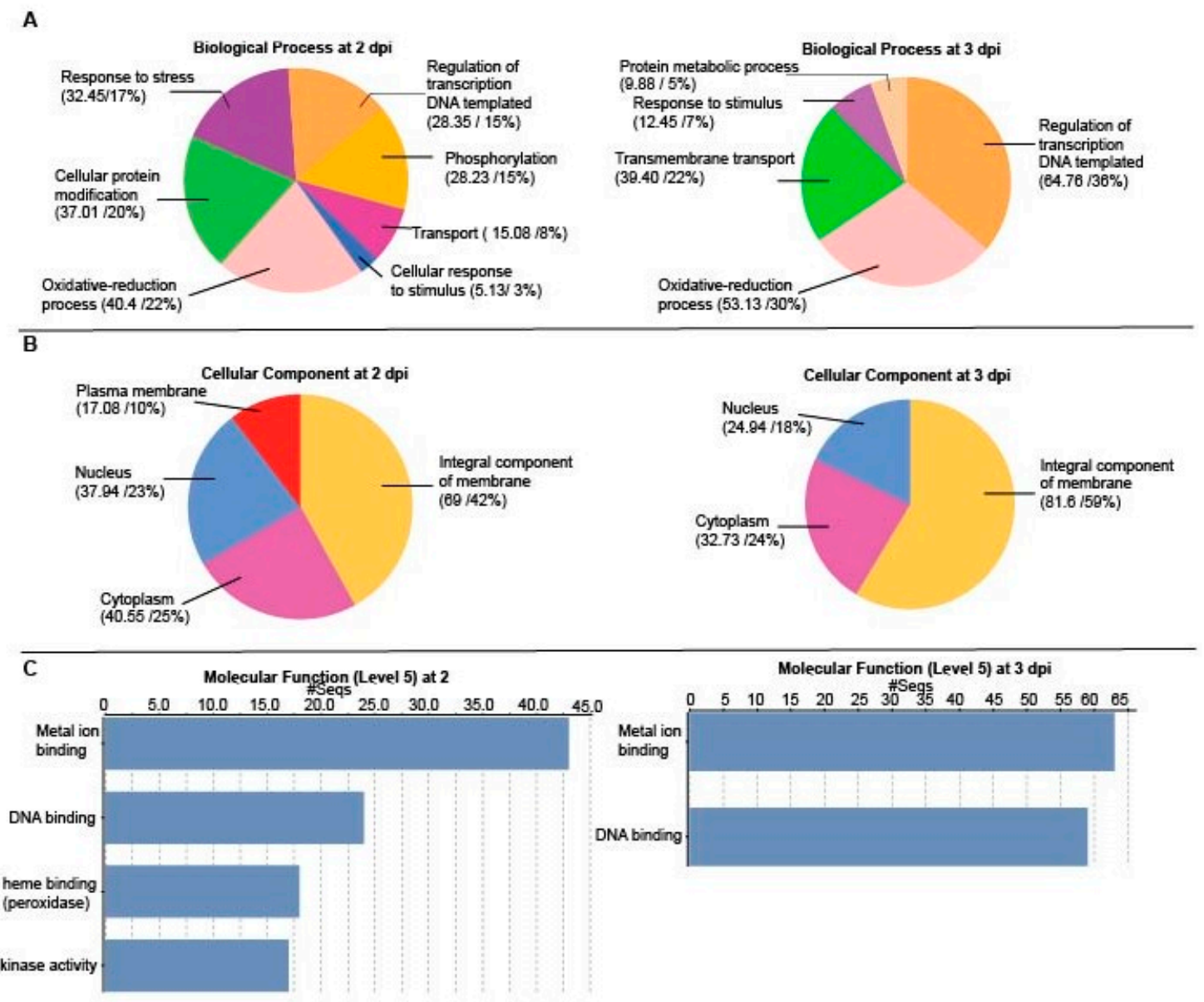

Figure 2. Summary pie charts and bar charts of GO analysis of DEGs that are upregulated transcripts at 2 and 3 dpi. The charts show the distribution of sequences according to the level 5 GO terms affiliated with (A) biological processes, (B) cellular components, and (C) molecular functions. The numbers and percentages of sequences are presented in parentheses with each slice in the pie charts.

Next, we searched the GO terms for downregulated genes at 2 and 3 dpi (Figure 3A). At 2 dpi the biological processes were distributed between $12 \%$ and $18 \%$ of total sequences associating with protein glycosylation and phosphorylation, transmembrane transport, oxidative-reduction process, developmental processes, metal ion transport, and carbohydrate metabolic process. Cellular lipid metabolic processes were $5 \%$ of sequences. At $3 \mathrm{dpi}$ the sequences were distributed from $5 \%$ to $18 \%$ of the total across protein phosphorylation, transmembrane transport, oxidation-reduction process, lipid metabolic process, carbohydrate metabolic process, regulation of transcription, organic substance transport, and response to stimuli (Figure 3A). Noting that similar GO IDs occur in upregulated and downregulated datasets suggest that PVX might target and carefully manipulate specific pathway regulatory nodes. 


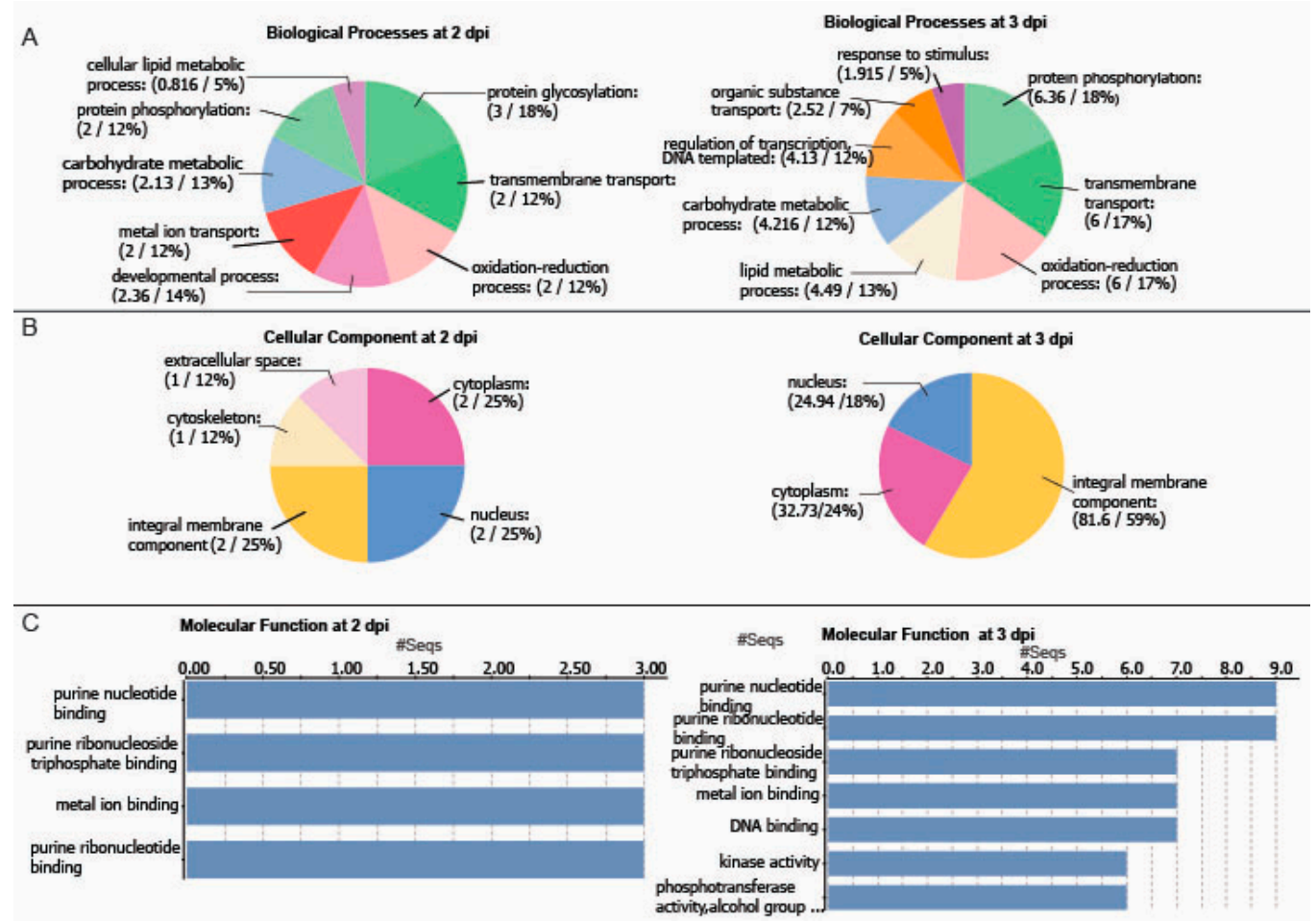

Figure 3. Summary pie charts and bar charts of GO analysis of DEGs that are downregulated transcripts at 2 and 3 dpi. The charts show the distribution of sequences according to the GO terms affiliated with (A) biological processes, (B) cellular components, and (C) molecular functions. The numbers and percentages of sequences are presented in parentheses with each slice in the pie charts.

Examining the cellular components GO terms, at 2 dpi between 12 and $25 \%$ of total sequences associate with the cytoplasm, nucleus, integral membrane component, cytoskeleton and extracellular space (Figure 3B). At 3 dpi there were only three cellular components GO terms with $18 \%$ of sequences representing the nucleus, $24 \%$ associating with the cytoplasm, and 59\% associating with integral membrane component (Figure 3B). Four downregulated molecular functions at $2 \mathrm{dpi}$ (Figure 3C) were: purine nucleotide binding, purine ribonucleoside triphosphate binding, purine ribonucleotide binding and, metal ion binding. At 3 dpi, the categories of molecular functions expand to include DNA binding, kinase activity, and phosphotransferase activity.

\subsection{Differentially Regulated Transcription Factors (TFs) at 2 and $3 \mathrm{dpi}$}

TFs within the AP2/ERF, bZIP, MYB, NAC, and WRKY families control important nodes in gene regulatory networks and metabolic adjustment to environmental factors [30,31]. Investigating TFs that target genes in abiotic and biotic stress tolerance is essential toward understanding traits at the molecular level that may be useful for genetic selection in breeding or engineering stress-tolerant crops [32,33]. We searched the PVXinduced potato transcriptome for TFs and then identified the Arabidopsis orthologues. The Venn diagram in Figure 4A shows that 31 TFs were upregulated at 2 dpi and 63 TFs at 3 dpi with thirteen TFs commonly upregulated at both days (Figure 4A and Table S4). There were two TFs downregulated at 2 dpi contributing to 24 TFs downregulated at 3 dpi (Figure 4A, Table S5). We tabulated factors belonging to $24 \mathrm{TF}$ families that are upregulated and $13 \mathrm{TF}$ families that are downregulated (Figure 4, Tables S4 and S5). 
A

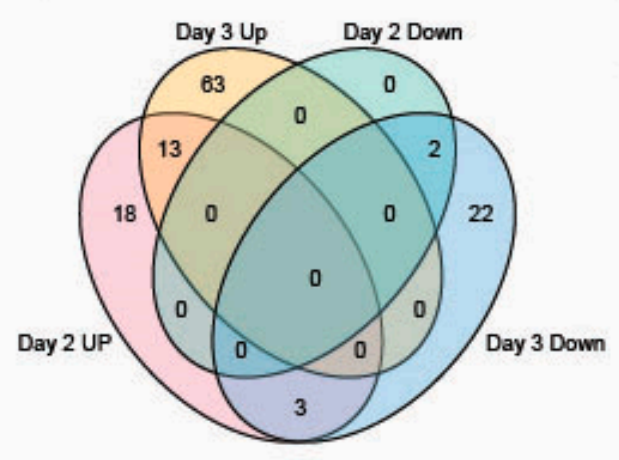

C Upregulated at $3 \mathrm{dpi}$ SoltuDM.11G011390.1

U Soltu DMOOG021250

Z SoltuDM.07G024010.

Soltu DM.CEG001380.

Solhu DM D6 G027190.

Solu DM.ORGO04560.2

m Soltu DM Co6G025880.1

¿ Soltu DM.06G004700.

Soltu DM.01G031190.1

a Soltu DM.10G015000.1

Nolu DM.07G020410.

SoltuDM D6GO02740.1

Soltu DM C2G030370.1

Solu DM.11G011130 1

Soltu DM. 10G015450.1

Soltu DM. 10G015440.1

Soltu DM. D8 G024240.

Soltu DM.07G012980.1

Soltu DM. DeGO15880

Solhu DM. .56020210.

Soltu DM COBG034330.1

Soltu DM.03G031550.1

Soltu DM.C3GO16750.1

Solu DM. D3G016740.

Solw DM C2GO28690. 1

Solhu DM O1G047780

Soltu DM.07G007140

Soltu DM. 11 G002810.

Solu DM. C8G028390.1

Soltu DM.05G021130

Soltu DM.04G005890.

Soltu OM.02G027330.1
B Upregulated at 2 dpi

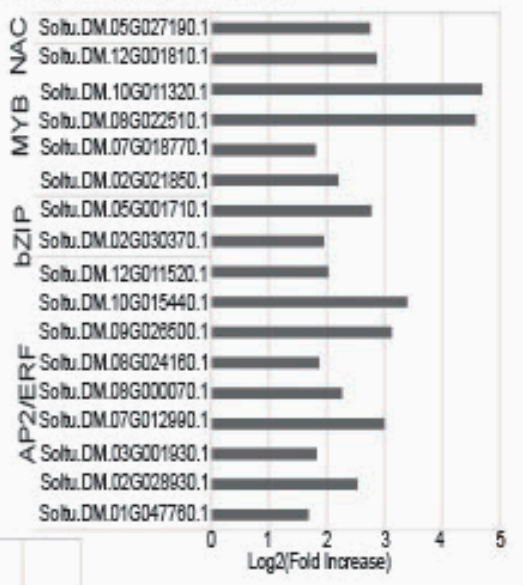

Figure 4. Differentially expressed transcription factors (TFs). (A) Venn diagram visualizing the overlap of differentially expressed TFs at 2 and 3 dpi. (B,C) Bar graphs show identifiers for genes that are upregulated at 2 and $3 \mathrm{dpi}$, respectively, with a cut-off value of $>1.0$. The TF families include: NAC, MYB, bZIP, and AP2/ERF.

We focused our attention on four TFs families that are known to contribute to environmental stress responses in plants NAC, MYB, bZIP, and AP2/ERF noting that there was between 1.5- to 8-fold increase in gene expression due to PVX-GFP infection (Figure 4B,C). Combining 2 and 3 dpi datasets, thirty-three upregulated TFs belong to the APATELA2 (AP2) family (Table S4) which is involved in responses to abiotic stress and phytohormone signaling. The AP2/ethylene-responsive factor (AP2/ERF) family is crucial for regulating a network of genes that promote plant survival to environmental stresses $[30,31,34]$. The dehydration-responsive element binding (DREB) factors are a subfamily of AP2/ERF TFs [35]. Interestingly, the potato homologs for the Arabidopsis C-repeat binding factor 2 (CBF2)/DREB1C, CBF4/DREB1D, DREB26 were upregulated which also engage in drought and cold tolerance (Table S4) [35]. 
The bZIP TF family is central to the regulation of developmental and physiological responses as well as abiotic and biotic stress responses [36-38]. Five of TFs (StbZIP37, StbZIP42, StbZIP46, StbZIP58, and StbZIP61) are upregulated early in PVX infection and only one (StbZIP72) is downregulated (Tables S4 and S5). Prior studies showed StbZIP60 is induced at $5 \mathrm{dpi}$ following PVX infection in potatoes and its absence from this dataset suggests it is not among the earliest TFs that are induced by PVX infection [15,17].

In plants, MYB TFs are involved in responses to biotic and abiotic stress, development, metabolism, cell cycle control, and defense [39-42]. Nine MYB factors are upregulated and eight are downregulated at 2 or 3 dpi (Tables S4 and S5). The Arabidopsis orthologs (MYB3, MYB15, MBY61, MYB85, and MYB125/DUO1) are involved in ABA responses, cold tolerance, secondary metabolism, stomata aperture, lignin biosynthesis, and pollen development [43]. Interestingly, the downregulated MYB83 is a known target for the microRNA (miRNA)159c that is also activated by drought stress in Arabidopsis [43].

The NAC factors are plant-specific TFs and are involved in embryonic, floral, and vegetative development. NAC factors are also involved in lateral root formation, auxin signaling, pathogen defense, abiotic stress, and ER stress. Early research identified a StNAC factor involved in responses to Phytophthora infestans [44]. AtNAC28 binds to the turnip crinkle virus (TCV) capsid leading to a hypersensitive response. Looking at the dataset in Table S4, the potato homolog of AtNAC28 is also upregulated as well as six other NACs that have not yet been characterized $[44,45]$.

The WRKY TF family in plants mediate responses to pathogens infection, wounding, drought, and cold. On the potato ortholog for WRKY41 is upregulated at $2 \mathrm{dpi}$ and then down-regulated at 3 dpi.

\subsection{Identification of Upregulated Pathogen Resistance Gene Analogs (RGA)}

Considering the identified GO terms for biological processes included responses to stimuli and oxidative reduction, alongside kinase activities as a prominent GO term for molecular functions, we hypothesized that pathogen innate or adaptive immune systems are likely engaged in early responses to infection [46]. R genes linked to host immunity typically have transmembrane (TM) domains, nucleotide-binding site (NBS) and leucinerich repeats (LRR) [47-50] and activate signaling cascades to alter nuclear gene expression. Salicylic acid activates mitochondrial signaling and affects redox regulation in a manner that is known to inhibit virus replication and movement $[46,49,50]$. While most $R$ genes are transcribed in tissues at basal levels, there are examples where pathogen challenge induces R gene expression [51-54]. Therefore, we used the Disease Resistance Analysis and Gene Orthology (DRAGO 2) pipeline of RGAugury to predict RGAs in the PVX induced transcriptome (Figure 5A) [55,56].

The CNL (CC-NBS-LRR) and TNL (TIR-NBS-LRR) proteins are subcategories of NBSencoding proteins specifically targeting pathogen effector proteins inside the host cell for effector-triggered immunity. Five NBS containing proteins were upregulated at 2 and 3 dpi (Figure 5B,C). We also searched the SolariX (cibiv.at/SolariX) compendium of NBS domain-containing proteins and the Spud DB (Solanaceae.plantbiology.msu.edu) using gene IDs [55]. Table S6 shows seven NBS containing proteins, including the newly identified Soltu.DM.01G023270.1, and Soltu.DM.05G006210.1, which DRAGO2 and RGAugury identified as a TM-CC class protein although having an NBS domain $[55,56]$. Three NBS containing proteins are specifically involved in responses to Pseudomonas syringae, P. infestans, or Meloidogyne javanica, while two NBS proteins represent ABC-2 transporter proteins involved in metabolic functions $[47,51,56]$. 


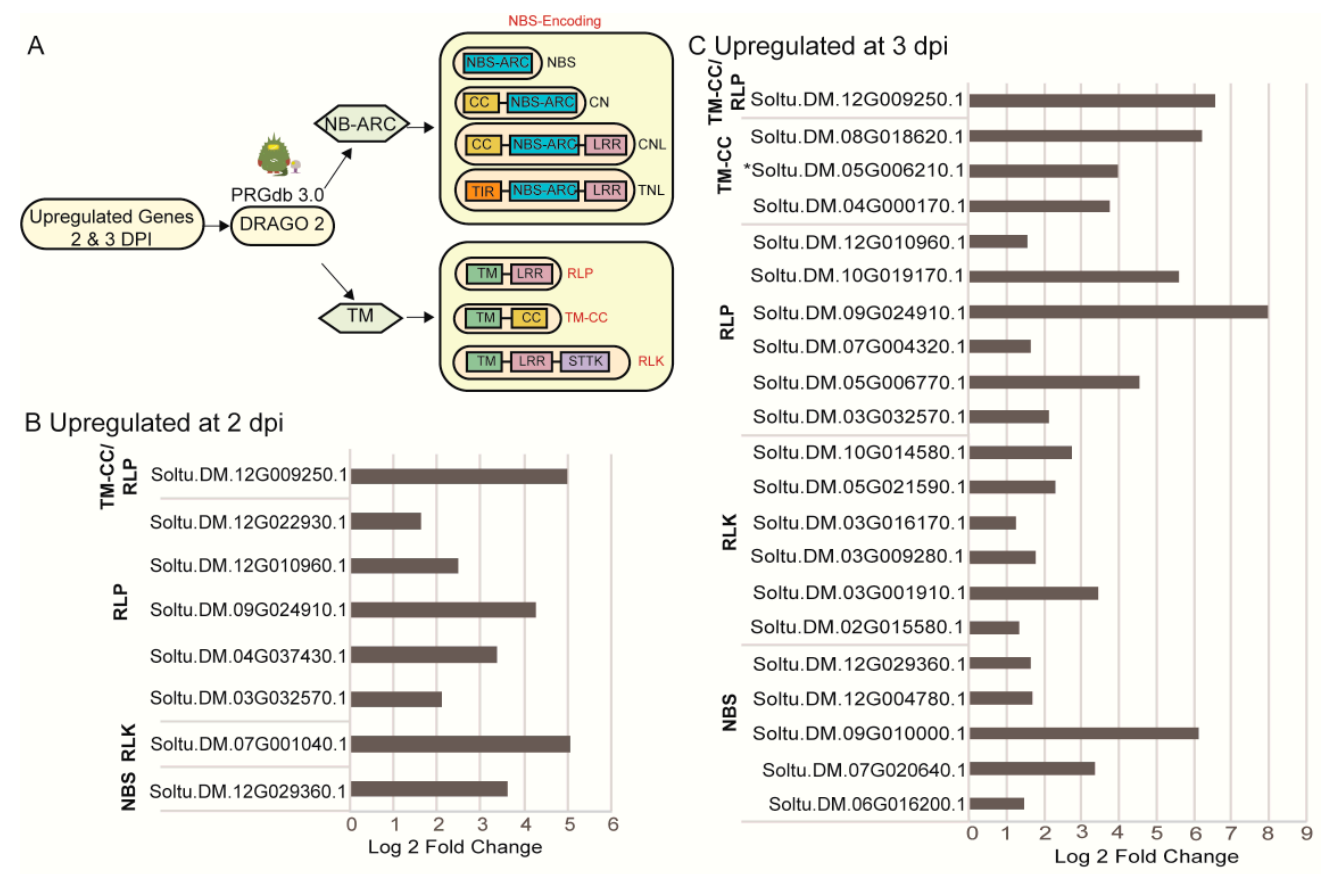

Figure 5. Upregulated RGAs identified using the DRAGO 2 pipeline. (A) Diagrammatic representation of the discovery pipeline based on protein domains such as nucleotide-binding site (NB-ARC), leucine-rich repeat (LRR), transmembrane domain (TM), coiled-coil (CC), Toll/Interleukin-1 receptor (TIR), lysin motif (LysM), and the serine/threonine and tyrosine kinase (STTK). RGA categories are identified in red: NBS-encoding, RLP, TM-CC, or RLK. Subcategories within the NBSencoding genes are identified inside yellow bubbles. (B,C) Bar graphs show genes that were upregulated at 2 and $3 \mathrm{dpi}$, respectively. The putative gene families are identified on the left. Asterisk places next to Sotu.DM.05G006210 identifies a gene that is classified at TM-CC but also has an NB-ARC domain so it potentially can be classified as a CNL.

The majority of upregulated RGAs belong to the RLP (TM-LRR) and RLK (TM-LRRSTTK) classes of proteins, suggesting that PVX infection stimulates PAMP/MAMP triggered immunity. Given that RLPs contribute to defense and plant development, we used the gene IDs to search within the SolariX or Spud DB for their functions (Table S6). We identified gene homologs for Too many mouths (TMM) and ERECTA, which engage in stomata development and distribution. One gene encodes a TM-CC protein that is a potential uridine kinase and normally attributed to developmental pathways. Homologs for Ve1, $E F-T u, B A K 1$ are linked to PAMP/MAMP triggered immunity involving bacterial and fungal pathogens (Table S6).

We mapped the chromosomal distribution of the RGAs analyzed onto the 12 chromosomes and found the loci did not cluster (Figure 6). Each Chr1, Chr2, Chr6, and Chr8 have one PRG locus, each Chr4, Chr9, Chr10 have 2 PRG loci, and each Chr5, Chr7 have three PRG loci. Chr3 and Chr 12 have four and five loci, respectively.

\subsection{DEGs Associated with the Unfolded Protein Response (UPR) that Are Common between Potato and Arabidopsis}

The unfolded protein response (UPR) monitors and responds to disruptions in the protein folding capacity in the ER caused by environmental stress. Previously we showed that the UPR serves to restrict the accumulation of PVX and a related virus Plantago asiatica mosaic virus (PLAMV) in N. benthamiana, A. thaliana, and S. tuberosum [15,17,57]. To discover whether UPR downstream genes were among the DEGs in the PVX-induced transcriptome, we compared the potato transcriptome dataset with a published transcriptome dataset of ER stress-regulated genes reported by Song et al. (2015) produced in Arabidopsis treated with tunicamycin $(5 \mu \mathrm{g} / \mathrm{mL}$ for $4 \mathrm{~h})$ [58]. This Arabidopsis study identified 286 upregulated ( $\geq 2$-fold) and 170 downregulated genes ( $\leq 0.5$-fold) using Agilent oligo microarray technology. We compared the PVX-induced transcriptome at 2 and 3 dpi with the single 
time point of the Arabidopsis dataset to determine which DEGs might be affiliated with UPR signaling pathways and presented the data using an UpSet plot (Figure 7). As a shorthand for representing the comparisons of S. tuberosum and Arabidopsis dataset we used S.t. $x$ A. t. indicating DEGs that are upregulated (Up x Up) or downregulated (Down $\mathrm{x}$ Down) in both datasets or alternatively upregulated and downregulated (Up x Down, Down $\times$ Up) in each dataset. We separately compared the $S$. tuberosum DEG datasets at 2 dpi and 3 dpi with the same Arabidopsis DEG dataset.

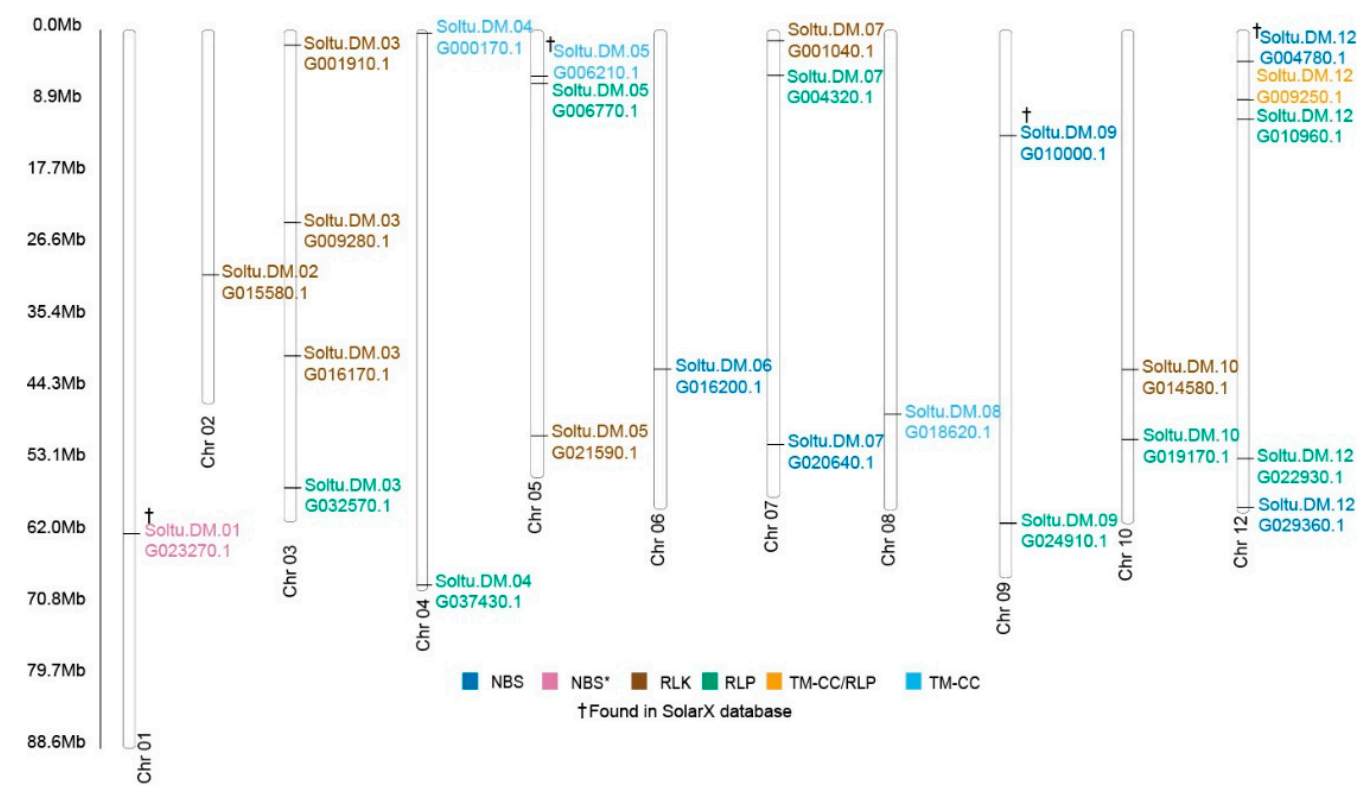

Figure 6. Distribution of the PVX-upregulated PRG analogs along S. tuberosum chromosomes. The scale indicates the genome size of S. tuberosum in Mb. Genes are color-coded according to the legend in the figure. " + " genes in the SolariX database search.

At 2 dpi, 20 total genes were induced in the S. tuberosum with identified homologs in the Arabidopsis datasets (Table S7). Only seven genes were upregulated at $2 \mathrm{dpi}$ which is identified in the graphic as " $2 \mathrm{dpi}$ UpxUp" and marked with a single circle under the plot. Ten genes were upregulated at 2 and $3 \mathrm{dpi}$ which is indicated by linked circles between 2dpi UpxUp and 3dpi UpxUp (Figure 7). Three genes were upregulated at $2 \mathrm{dpi}$ but downregulated at $3 \mathrm{dpi}$ as indicated by the linked circles below the bar graph as $2 \mathrm{dpi}$ UpxUp and 3 DownxDown (Figure 7). At 3 dpi there were a total of 31 upregulated genes. This total is the sum of 19 genes that were upregulated in both S. tuberosum and Arabidopsis (UpxUp) at 3 dpi only, ten genes that were upregulated in both hosts at 2 and $3 \mathrm{dpi}$, and two genes were upregulated at 3- dpi but downregulated at $2 \mathrm{dpi}$ (represented by linked circles). Notably considering genes that are primarily downregulated in the Arabidopsis dataset, we identified eight upregulated genes at 2 dpi, 18 upregulated genes at $3 \mathrm{dpi}$, and 9 upregulated genes at 2 and 3 dpi. We identified six downregulated genes in the potato transcriptome at $2 \mathrm{dpi}$. Twenty-five genes were downregulated genes at $3 \mathrm{dpi}$ (Figure 7, Table S8). 


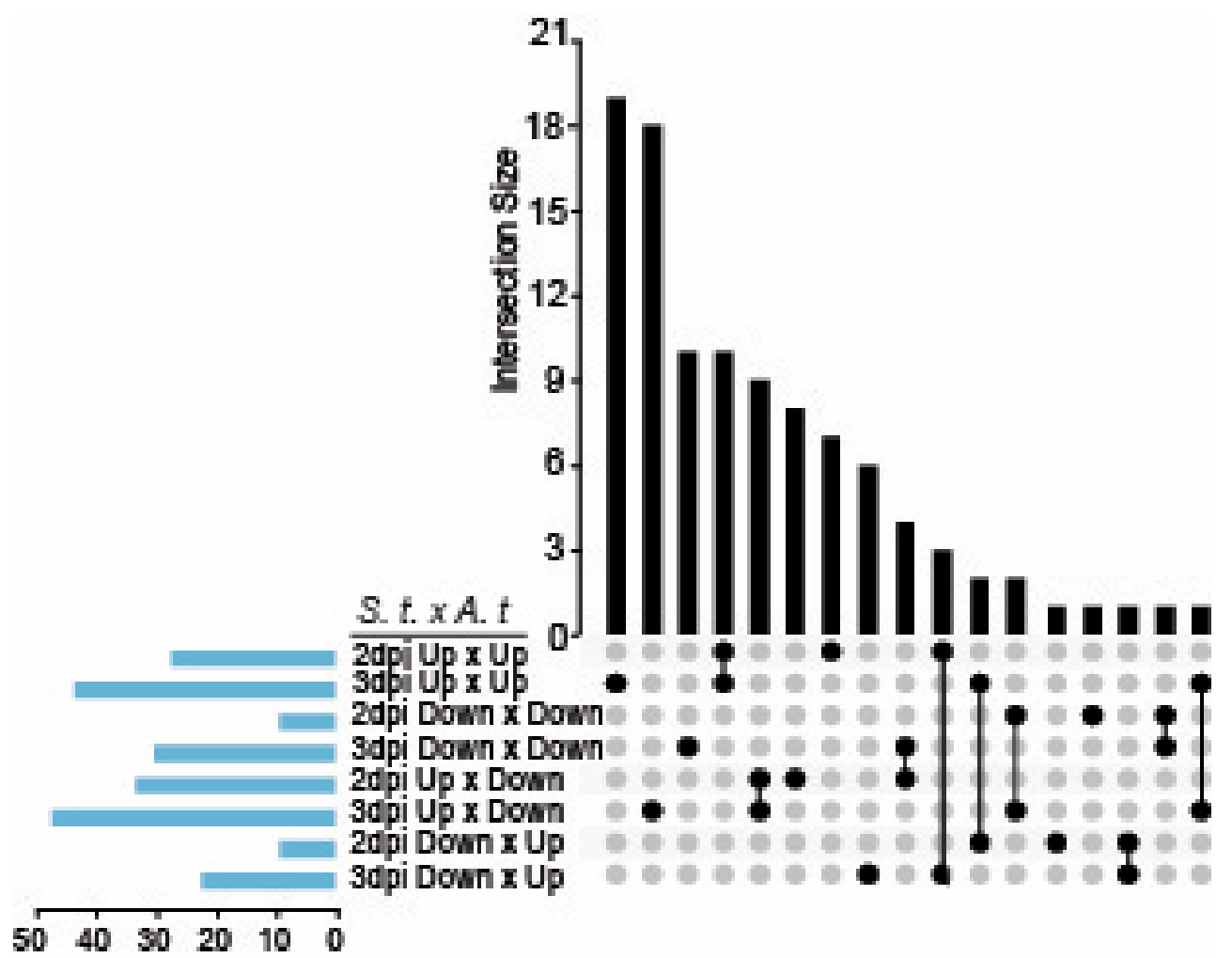

Figure 7. Functional characterization of UPR related genes in S. tuberosum DEGs. The UpSet plot shows potato DEGs ( 2 dpi and $3 \mathrm{dpi}$ ) that were also represented in a published Arabidopsis UPR DEGs dataset obtained following induction by tunicamycin $(5 \mu \mathrm{g} / \mathrm{mL})$ [58]. S.t. $x$ A.t is shorthand for S. tuberosum by Arabidopsis comparison indicating DEGs that are upregulated or downregulated in both datasets or alternatively up and down regulated in each dataset.

Next, we closely examined the gene model descriptions attributed to the Arabidopsis genes to functionally characterize the genes identified as common to the S. tuberosum and Arabidopsis datasets (Tables S7 and S8). Considering the upregulated genes across 2 and $3 \mathrm{dpi}$, we identified six major activities: (1) UPR and ER-associated protein degradation (ERAD), (2) plasmodesmata and cell wall functions, (3) cargo transport, (4) disease resistance, systemic acquired resistance, oxidative stress, (5) transcription and DNA functions, (6) abiotic stress responses. The UPR is a mechanism that refolds malformed proteins in the ER. The ERAD machinery degrades proteins that cannot be refolded. There are four factors involved in these responses that were commonly activated by PVX infection and ER stress treatment in Arabidopsis. Glycosyltransferase plays a role in protein glycosylation and maturation [59]. Cytochrome P450 has multiple specificities and is a co-factor binding Bax inhibitor 1 in the ER which is a regulator of UPR signaling [60]. HRD1 is a ubiquitin ligase and F-box protein complex with ubiquitin ligases to modify protein substrates for degradation [61].

Regarding plasmodesmata and cell wall functions, pectin lyases, pectin esterases, and remorins have been identified as factors that recognize invading viral pathogens and regulate virus cell-to-cell movement. The PVX 25K protein is reported to bind remorin [62-64]. WAK-like receptor-like kinases function in gene-for-gene resistance and recognize apoplastic efforts to confer pathogen resistance [65]. The carbohydrate-binding $\mathrm{X} 8$ domain protein binds to callose at the aperture of plasmodesmata. The X8 domain proteins regulate the expansion or constriction of the plasmodesmal aperture to control cell-to-cell communication and virus intercellular movement [66]. Regarding cargo transport, the ER-localized p24 protein is a type-I membrane protein that associates with the Golgi and cargo vesicles and is sometimes involved in transporting GPI-anchored proteins to the plasma membrane [67-69]. 
Regarding disease resistance, several genes were identified that play various roles in broad pathogen resistance including $\mathrm{R}$ gene-mediated resistance, oxidative stress, and systemic acquired resistance: HIN1/NDR1, lipase, NAC28, UDP-glycosyltransferase, cysteinerich $R L K$, and cytochrome $p 450[24,45,47,60,70-72]$. None of these factors were specifically antiviral except for AtNAC28, which restricts TCV infection. Genes that play known roles in drought, heat, and salt stress are cytochrome p450, CYP709B3 (a relative of cytochrome p450), UDP-glycosyltransferase, and LEA family members [24,73-75]. Four genes encode known transcription factors: ZPT2, MADS-box TF, ZFHD1, and AtNAC28, and one factor likely regulates DNA functions, Ring/UBox E3 ligase. These data suggest that PVX may use the UPR machinery to reprogram gene expression during infection.

\section{Discussion}

This study examines the potato gene expression profile during the early days of PVX-GFP infection. We mined a transcriptome dataset for DEGs that are up- or downregulated to understand the host genetic responses and identify key regulatory networks that respond to PVX infection. Surprisingly, the upregulated and downregulated genes changed significantly between 2 and $3 \mathrm{dpi}$. To better understand these genetic responses, we used GO analysis to cluster DEGS into common biological processes, cellular components, and molecular functions at 2 and $3 \mathrm{dpi}$. A significant portion of DEGs is generally reported to respond to environmental stimuli and stress, oxidative-reductive processes, transcription factors, protein modifications, and metabolic processes, and membrane transport. The pattern of GO terms led us to investigate the TFs, RGA, and UPR responsive genes that may be induced or suppressed to test the hypothesis that PVX infection stimulates early genes involved in broad cellular adaptive and defense responses.

Transcriptional regulatory networks are crucial for plant adaptation to adverse environments including heat, drought, cold, and pathogen attack [76]. Plant viruses are known to alter their cellular environments to create conditions that support infection, or to create leaf environment conditions that attract herbivorous insects which may also act as vectors for virus dispersal. PVX infection associated transcriptional regulatory networks have been largely unexplored. In this study, a total of 107 TFs were upregulated at 2 and 3 - dpi while only 27 TFs are downregulated. For example, thirty-one upregulated factors belong to the AP2 family that primarily engage in regulatory networks associated with drought tolerance, ethylene response, and oxidative signals [77]. The AP2 factors typically ensure plant resiliency in adverse environments and it is worth speculating that these factors coordinate metabolic adjustments to ensure plant survival to PVX infection. The bZIP, HSF, MYB, NAC, WRYK factors identified in Table S4 belong to TF families that are known to bolster host survival. Previous investigations of PVX and the related potexvirus, Plantago asiatica mosaic virus (PlAMV), identified TFs such as bZIP60, bZIP28, and NAC089 which contribute to regulating antiviral responses in susceptible hosts [15]. These three TFs were not identified among the DEGs in the present study and prior investigations suggest that bZIP60 is activated in potato plants between 3 and 5 dpi. Five StbZIPs activated by PVX infection include StbZIP42, StbZIP58, StbZIP46, StbZIP61, and StbZIP37 [27]. Interestingly StbZIP42 and StbZIP61 are reported to be highly repressed following treatment with heat. StbZIP42 is also repressed following treatment with P. infestans, BABA or BTH [27]. StbZIP58 is highly induced following heat treatment [27].

Two previous studies reported responses to PVY infection in susceptible and resistant potatoes within the first $48 \mathrm{~h}$ of infection and while there were significant shifts in photosynthetic metabolism, redox-regulation, only individual WRKY, MYB, and DOF factors were identified as differentially expressed TFs [24,78]. Our study has uncovered a comparatively large number of TFs when compared with the previous studies looking at the plant virus interactions through transcriptome and proteome approaches [22,24,78-81]. The TFs identified in this Tables S4 and S5 have not been functionally characterized although there is sufficient sequence information to assign them to homology-based TF families. 
Further analysis is needed to determine the physiological implications of coordinated TF expression patterns, and their role in virus infection.

Innate immunity to plant viruses is controlled by single dominant or recessive $\mathrm{R}$ genes encoding factors that inhibit various stages in the virus infection cycle. Innate immunity is a form of basal immunity that is triggered by recognition of a specific effector protein that can derive from a specific virus species or strain. Effector triggered immunity (ETI) activates a broad range of local and systemic defense responses following pathogen recognition including protein kinase cascades $[14,46,82]$. Induced antiviral defense mechanisms such as systemic acquired resistance (SAR) involve the oxidative burst, expression of defenserelated genes, and phytohormones such as salicylic acid (SA), jasmonic acid (JA), abscisic acid (ABA), azelaic acid (AZA), and glycerol-3-phosphate [46]. Prior studies showed that exogenous treatment of $N$. benthamiana leaves with SA activates alternative oxidase (AOX) in the mitochondria which play an important role in basal resistance to PVX [83]. In this study, we used GO term analysis to initially categorize DEGs and we identified clusters of sequences involved in cellular responses to stimuli or stress, kinases, and oxidative-reduction processes which are features usually associated with innate or induced immunity to virus infection. As the various defense-related phytohormones inducing a broad range of signaling pathways, the most straight forward approach to investigate whether basal immunity might be activated was to search the transcriptome for RGAs. Recent transcriptomic studies have led to the identification of RGAs in the model and non-model systems that are induced by pathogen effectors and virulence factors $[51-54,83]$. We searched for RGAs in the PRGdb and SolariX database and identified seven NBS containing, four RLP and two RLK genes. It is remarkable to see such early transcriptional changes that reflect $\mathrm{R}$ gene recognition of virulence factors although we do not know which viral features stimulate this host-mediated response. Generally, R gene-mediated responses involve either extreme resistance or hypersensitive cell death. However, recent transcriptome analysis in cassava challenged with South African cassava mosaic virus (SACMV) identified transcriptionally upregulated RGAs that play crucial roles in tolerance and recovery to geminivirus infection [84]. In this model, RGAs are proposed to provide surveillance in a manner that might lower SACMV replication and reduce symptoms. Such a model might also explain the mild symptoms caused by PVX infection in potato plants. On the other hand, evidence that multiple RGAs are stimulated that were identified as having putative roles in bacterial and fungal resistance suggesting that broad-spectrum resistance may be activated as a consequence of PVX infection. Perhaps PVX infection stimulates multiple RGAs to exclude competing pathogens that may challenge the same host $[47,83]$. Another possibility is that virus infection stimulates the expression of RGAs which are maintained by the cell in a signal competent but an auto-inhibited state. It is possible that early activation of transcription leads to higher levels of RGAs but these specific $R$ proteins identified in this study failed to activate cellular defenses. Perhaps one or more of these RGA proteins heterodimerize with other R protein partners to activate antiviral defenses and that such partners are not available [85]. In this model, the RGAs detect but fail to counteract virus invasion. Further research is needed to explore the role of these RGAs in creating a state of PVX tolerance or broad-spectrum resistance.

The ER is a central hub for responses to adverse environmental challenges such as virus infection, heat, chemical, osmotic, and salt stress [86]. The physiological consequences of prolonged low-level ER stress include constrained plant development and productivity, whereas chronic stress can result in death and crop losses. The transmembrane sensors of ER stress in plants are the inositol requiring enzyme 1 (IRE1), bZIP28, and bZIP17 [87]. These well-known monitoring/sensing pathways use the transcription factors bZIP60, bZIP28, and bZIP17 to activate cellular adaptive responses. They coordinate the transcription of molecular chaperones, including the ER lumen binding protein (BiP). Current research has shown that the PVX TGB2 and TGB3 proteins are movement proteins that are embedded in the ER. TGB3 is specifically recognized by the IRE1/bZIP60 as well as the bZIP17 pathways which coordinate to restrict virus movement [15]. We downloaded 
a published Arabidopsis dataset that represents ER stress- induced genes that promote protein homeostasis in leaves treatment with tunicamycin [58]. By comparing the PVX induced transcriptome dataset in potato with the Arabidopsis dataset [58] we identified common candidate genes that contribute to ER stress response and virus infection. Surprisingly when we compared these datasets, we identified only 51 common DEGs, and none of these encode protein folding enzymes or chaperones that reside in the ER, which are typically UPR downstream genes. The UPR related genes in the dataset include glycosyl transferase and cytochrome $\mathrm{p} 450$. The presence of glycosyltransferase reflects a need to enhance protein modifications coupled with protein folding. Interestingly, HRD1 and F-box proteins that are attributed to ERAD were increased which are necessary for degrading malformed proteins that cannot be refolded in the ER. We identified several cargo functions that might complement increasing protein synthesis brought on by virus infection. There are also increases in plasmodesmata functions which are likely important for regulating virus cell-to-cell trafficking. We identified several factors that engage in cellular adaptation to abiotic and biotic stress as well as disease resistance. We also identified a set of transcription factors that have not been previously studied for their role in ER stress management. In Table S4 there are three heat shock transcription factors identified which have homologs in Arabidopsis that have been linked to UPR regulation in the cytoplasm. Activation of these HSF factors may precede activation of the ER-resident sensors. A recent report links HSF transcription factors to sensing oxidative stress and enhancing UPR gene expression [88]. These data suggest that early UPR regulation is linked to several cellular adaptive responses occurring outside the ER and these responses encompass physiological processes beyond protein homeostasis.

\section{Materials and Methods}

\subsection{PVX Inoculation of Potato Leaves}

S. tuberosum cultivar 'Russet Norkota' (USDA Gene Bank Accession \# AV49) plants were propagated by cuttings on Murashige and Skoog medium (PhytoTech Labs, Lenexa, $\mathrm{KS}$ ). Rooted cuttings were potted and grown in a growth room with a $12 \mathrm{~h}$ photoperiod at $20^{\circ} \mathrm{C}$ for four weeks. The PVX-GFP infectious clone, maintained in Agrobacterium tumefaciens strain GV3101 [72], was delivered to N. benthamiana plants grown under $12 \mathrm{hr}$ light at $20^{\circ} \mathrm{C}$. Two $N$. benthamiana leaves were dusted with carborundum and mechanically inoculated. Then, the upper leaves were harvested after the appearance of symptoms (2 weeks), ground 1:10 (w/v) in $0.01 \mathrm{M}$ phosphate buffer (pH 7.0), centrifuged at $6000 \mathrm{rpm}$ for $5 \mathrm{~min}$, and then the soluble phase (sap extract) was stored at $-80^{\circ} \mathrm{C}$. Standard infectivity assays [71] to estimate the amount of infectious virus in the sap preparation were conducted to ensure that future reproducibility in which other researchers can sample leaves having the same number of infection sites, which likely influences the measurable transcriptome responses. Chenopodium quinoa leaves $(n=6)$ were rub-inoculated with $20 \mu \mathrm{L}$ of sap and the numbers of chlorotic foci were counted after 7-12 days to standardize the inoculum titer. Then, nine large terminal leaflets of compound potato leaves were mechanically inoculated with $20 \mu \mathrm{L}$ of sap after dusting with carborundum and three leaves were pooled for RNA extraction to create three separate RNA samples for RNAseq. Mock treatment was carried out using only $0.01 \mathrm{M}$ phosphate buffer (pH 7.0). Leaf samples were collected after 2-3 dpi, immediately frozen in liquid nitrogen, and stored at $-80^{\circ} \mathrm{C}$ freezer for further use [27]. Fluorescence imaging was carried out using Stemi SV11 Apo M²BIO and a 20× objective (Kramer Scientific Corp., alley Cottage, NY, USA) using GFP-470nm and GFP-500nm filters.

\subsection{RNA Extraction, $c D N A$ Library Construction, Filtering Sequencing Reads}

Total RNA was extracted using the RNeasy Mini Kit (Qiagen). RNA purity was assessed using Epoch 2 Microplate Spectrophotometer (BioTek, VT, USA). All samples produced $\mathrm{A}_{260} / \mathrm{A}_{280}$ ratios ranging between 1.9-2.1. RNA integrity was assessed using Agilent 2100 bioanalyzer (Agilent Technologies, Palo Alto, California) and all samples 
had an RNA integrity number (RIN number) $>7.3$ as described in Herath and Verchot (2021) [27].

The mRNA purification, fragmentation, cDNA synthesis, second-strand synthesis, adapter ligation, cDNA library purification, and transcriptomic sequencing was performed at the Beijing Genomics Institute (BGI, Shenzhen, China) using the BGISEQ-500 platform [89]. BGI performed PE150 strand-specific library preparation, generated raw data, and provided clean reads as follows. First, the polyA-containing mRNA was purified using oligo(dT)-coupled magnetic beads. Then, mRNA fragmentation was carried out using divalent cations under elevated temperature. The cleaved fragments were converted into the first-strand cDNA using reverse transcriptase and random primers. Then, secondstrand cDNA synthesis using DNA polymerase I and incorporating dUTP (2'-deoxyuridine $5^{\prime}$-triphosphate) in place of dTTP (2'-deoxyguanosine $5^{\prime}$-triphosphate). The cDNA library was prepared using DNA nano ball technology in the BGISEQ-500 platform, suited for high throughput transcriptome studies [27].

BGI used SOAPnuke (ver 2.1.0) for quality control and preprocessing of the raw data to eliminate adapters or low-quality sequences. The parameters for cutting adapters and setting length restriction were: 0.01 -1 20 -q 0.4 -A 0.25 -cutAdaptor -Q 2 -G -polyX50 -minLen 150, as explained in the SOAPnuke github.com repository [90]. FASTQC was used to assess read qualities (version 0.11.9). The subsequent analysis returned clean reads. The clean reads generated by BGISEQ-500 were submitted to the Sequence Read Archive database at NCBI under the bio project PRJNA679820 [27].

\subsection{Genome Mapping and Gene Expression Analysis}

Clean sequencing reads were mapped to the $S$. tuberosum reference genome (DM v6.1) available at SPUDdb (http:/ / solanaceae.plantbiology.msu.edu—last access date 28 January 2021) [25] using Hierarchical Indexing for Spliced Alignment of Transcripts 2 (HISAT2) [91]. Bio-SAMtool (version 1.9) was used for formatting and storing alignments as SAM files and companion BAM files [92]. Transcripts assembly and abundance were determined using StringTie (version 2.1.4) and annotated according to the reference genome (DM v6.1) [93] (Table S1). The bash script used for the analysis is available at https://github.com/venuraherath/PVX_Transcriptome_Analysis_last access date 2 February 2021. Then, the results were converted to DESEQ2 format using prepDE.py python scripts available in the program for differential expression analysis.

Differential sequence expression analysis was carried out using DESeq2 (version 1.28.1) in RStudio (version 1.3.959). DESeq2 performs differential analysis of count data. A list of differentially expressed genes at 2 and $3 \mathrm{dpi}$ was generated by testing the $\log _{2}$-fold changes between treatment and control and ranked as less than -1.2 or greater than 1.2 with a resulting $p$-value of $\leq 0.05$ that was adjusted using Benjamini and Hochberg's (FDR) method $[94,95]$. We used TBTools ver 1.0692 to prepare Volcano plots, Venn diagrams, and heat maps [96].

\subsection{Gene Ontology (GO)Enrichment Analysis}

BLASTp was used to find potential homologs using the $e$-value cut-off of $1 \times 10^{-3}$ against Viridiplanta proteins in NCBI non-redundant (nr) database. OmicsBOX ver. 1.4.11 (BioBam BioInformatics Solutions; biobam.com/omicsbox/—last access date 15 January 2021) was used to perform GO annotation. The fasta formatted protein sequences were used for a BLAST search against the NCBI nr database and the InterPro database (https: / / www. ebi.ac.uk/interpro/-last access date 15 January 2021) representing protein domains and families [97] using and an $e$-value hit filter of $1 \times 10^{-6}$ and cut-off of 55. The search results were merged, and sequence annotations were carried out using GO terms, considering GO hierarchy, quality, and abundance of the source annotations. To obtain functional information, the GO terms were classified at GO level 5 and a node-score of 5 for the complete list of DEGs Then, GO term enrichment analysis was carried out based on Fisher's exact test, and a $p$-value cutoff of 0.05 . 


\subsection{Functional Annotation of Transcription Factors and Resistance Gene Analogs (RGAs)}

Differentially regulated transcription factors among the DEGs and their orthologs in Arabidopsis were identified using The Protein Annotation with Z-scoRE server (PANNZER2, http: / / ekhidna2.biocenter.helsinki.fi/sanspanz/—last access date 10 January 2021) [98]. RGA identification was carried out using DRAGO 2 pipeline with default settings against both reference and putative genes included in the PRGdb 3.0 server (http:/ / prgdb.org/ prgdb /-last access date 20 January 2021) [55].

\subsection{Comparative Analysis of PVX Induced DEGs in Potato and Published Tunicamycin Induced} DEGs in Arabidopsis

DEGs induced by treatment of Arabidopsis seedlings with $5 \mathrm{ug} / \mathrm{mL}$ tunicamycin for $4 \mathrm{~h}$ were retrieved from Song et al.'s 2015 study (Supplementary Information (http: / / www. pnas.org/lookup/suppl/doi:10.1073/pnas.1419703112/-/DCSupplemental—last access date 10 December 2020) [59]. Reciprocal Blast was conducted against the Arabidopsis UPR induced genes to identify potential homologs genes with a minimum identity percentage of $90 \%$ using NCBI blast ver 2.9.0 . To visualize the intersection between the PVX-induced DEGs in potato at 2 and $3 \mathrm{dpi}$ with the tunicamycin induced DEGs in Arabidopsis and the sequences categorized as up or down-regulated, an UpSet plot was generated using TBtools version 1.074. Then, functional categorization of the identified genes was carried out using the GO annotation tool (https: / / www.arabidopsis.org/tools/bulk/go/index.jsp -last access date 12 December 2020) available at The Arabidopsis Information Resource (TAIR) database (https:/ / www.arabidopsis.org/—last access date 12 December 2020) [99]. Microsoft Excel and Adobe Illustrator 2020 were used to prepare and compile charts.

\section{Conclusions}

PVX is one of the major plant viruses that infect the Solanaceae family including potatoes. In this study, we showcase the transcriptional regulatory networks triggered during the early stages of the PVX infection. We identified 1242 DEGs spanning across 2 and 3 dpi. Interestingly, the majority of up-regulated DEGs are involved in stress response, redox regulation, as well as inter-and intracellular transport processes that coincide with the entry and the establishment of PVX infection. We also identified the key TFs and target genes involved in the pathogen response and UPR pathways. Further studies are required to functionally characterize the identified major transcription factors that potentially playing a major role in regulating general and specific responses to PVX infection.

Supplementary Materials: The following are available online at https://www.mdpi.com/1422 -0067/22/6/2837/s1, Figure S1: Standardization of PVX-GFP inoculum. (A,B) Infection foci on Chenopodium leaves at 4 and $7 \mathrm{dpi}$ were counted to determine the infectivity of the standard $20 \mu \mathrm{L}$ inoculum dose. (C,D) Representative potato plants that were inoculated with PVX-GFP and mock inoculum. (E,F) Fluorescence microscopic images showing PVX-GFP containing infection foci on inoculated potato leaves, Table S1: Summary of the RNA-sequencing statistics, Table S2: S. tuberosum genes that are upregulated at 2 and 3 days post-inoculation (dpi), Table S3: S. tuberosum genes that are downregulated at 2 and 3 days post inoculation (dpi), Table S4: Upregulated transcription factors at 2 or 3 dpi, Table S5: Downregulated transcription factors at 2 and 3 dpi, Table S6: Putative RGAs according to Spud and SolariX databases, Table S7: Primarily upregulated genes in PVX-infected $S$. tuberosum and tunicamycin treated Arabidopsis, Table S8: Primarily downregulated genes identified in PVX infected S. tuberosum and in tunicamycin treated Arabidopsis.

Author Contributions: Conceptualization, V.H. and J.V.; methodology, V.H., and J.V.; software, V.H.; validation, V.H., and J.V.; formal analysis, V.H.; investigation, V.H., and J.V.; resources, V.H., and J.V.; data curation, V.H.; writing—original draft preparation, J.V.; writing—review and editing, V.H., and J.V.; visualization, V.H., and J.V.; supervision, J.V.; project administration, J.V.; funding acquisition, J.V. All authors have read and agreed to the published version of the manuscript.

Funding: Funding for this research was provided by the National Science Foundation (1759034).

Institutional Review Board Statement: Not applicable. 
Informed Consent Statement: Not applicable.

Data Availability Statement: RNA-Seq data were deposited in Sequence Read Archive database at NCBI under the bio project PRJNA679820 [27].

Acknowledgments: Portions of this research were conducted with high performance research computing resources provided by Texas A\&M University (http://hprc.tamu.edu). We would like to acknowledge the support given By Keerti Rathore and his lab for acquiring fluorescent microscope images.

Conflicts of Interest: The authors declare no conflict of interest.

\section{References}

1. Spillane, C.; Verchot, J.; Kavanagh, T.A.; Baulcombe, D.C. Concurrent suppression of virus replication and rescue of movementdefective virus in transgenic plants expressing the coat protein of potato virus X. Virology 1997, 236. [CrossRef]

2. Heppler, M.; Verchot-Lubicz, J. Cell-to-cell movement of potato virus X proteins in different plant species. Microsc. Microanal. 2004, 10. [CrossRef]

3. Howard, A.R.; Heppler, M.L.; Ju, H.-J.; Krishnamurthy, K.; Payton, M.E.; Verchot-Lubicz, J. Potato virus X TGBp1 induces plasmodesmata gating and moves between cells in several host species whereas CP moves only in N. benthamiana leaves. Virology 2004, 328. [CrossRef]

4. Heinlein, M. Plasmodesmata: Channels for viruses on the move. Methods Mol. Biol. 2015, 1217, 25-52. [CrossRef] [PubMed]

5. Mekuria, T.; Bamunusinghe, D.; Payton, M.; Verchot-Lubicz, J. Phloem unloading of potato virus X movement protein is regulated by virus and host factors. Mol. Plant Microbe Interact. 2008, 21, 1106-1117. [CrossRef] [PubMed]

6. Tilsner, J.; Oparka, K.J. Missing links?-The connection between replication and movement of plant RNA viruses. Curr. Opin. Virol. 2012, 2, 699-705. [CrossRef]

7. Huang, X.; Stein, B.D.; Cheng, H.; Malyutin, A.; Tsvetkova, I.B.; Baxter, D.V.; Remmes, N.B.; Verchot, J.; Kao, C.; Bronstein, L.M.; et al. Magnetic virus-like nanoparticles in N. benthamiana plants: A new paradigm for environmental and agronomic biotechnological research. ACS Nano 2011, 5. [CrossRef]

8. Wang, A. Dissecting the molecular network of virus-plant interactions: The complex roles of host factors. Annu. Rev. Phytopathol. 2015, 53, 45-66. [CrossRef]

9. Tilsner, J.; Linnik, O.; Louveaux, M.; Roberts, I.M.; Chapman, S.N.; Oparka, K.J. Replication and trafficking of a plant virus are coupled at the entrances of plasmodesmata. J. Cell Biol. 2013, 201, 981-995. [CrossRef]

10. Sasvari, Z.; Alatriste Gonzalez, P.; Nagy, P.D. Tombusvirus-yeast interactions identify conserved cell-intrinsic viral restriction factors. Front. Plant Sci. 2014, 5, 383. [CrossRef]

11. Verchot, J. Cellular chaperones and folding enzymes are vital contributors to membrane bound replication and movement complexes during plant RNA virus infection. Front. Plant Sci. 2012, 3, 275. [CrossRef]

12. Verchot, J. Wrapping membranes around plant virus infection. Curr. Opin. Virol. 2011, 1. [CrossRef] [PubMed]

13. Csorba, T.; Kontra, L.; Burgyán, J. Viral silencing suppressors: Tools forged to fine-tune host-pathogen coexistence. Virology 2015, 479, 85-103. [CrossRef] [PubMed]

14. Meier, N.; Hatch, C.; Nagalakshmi, U.; Dinesh-Kumar, S.P. Perspectives on intracellular perception of plant viruses. Mol. Plant Pathol. 2019, 20, 1185-1190. [CrossRef] [PubMed]

15. Gayral, M.; Arias Gaguancela, O.; Vasquez, E.; Herath, V.; Flores, F.J.; Dickman, M.B.; Verchot, J. Multiple ER-to-nucleus stress signaling pathways are activated during plantago asiatica mosaic virus and turnip mosaic virus infection in Arabidopsis thaliana. Plant J. 2020, 103, 1233-1245. [CrossRef] [PubMed]

16. Zheng, X.; Fahlgren, N.; Abbasi, A.; Berry, J.C.; Carrington, J.C. Antiviral ARGONAUTEs against turnip crinkle virus revealed by image-based trait analysis. Plant Physiol. 2019, 180, 1418-1435. [CrossRef] [PubMed]

17. Gaguancela, O.; Zúñiga, L.P.; Arias, A.V.; Halterman, D.; Flores, F.J.; Johansen, I.E.; Wang, A.; Yamaji, Y.; Verchot, J. The IRE1/bZIP60 pathway and bax inhibitor 1 suppress systemic accumulation of potyviruses and potexviruses in Arabidopsis and Nicotiana benthamiana plants. Mol. Plant Microbe Interact. 2016, 29, 750-766. [CrossRef]

18. Shukla, A.; López-González, S.; Hoffmann, G.; Hafrén, A. Diverse plant viruses: A toolbox for dissection of cellular pathways. J. Exp. Bot. 2019, 70, 3029-3034. [CrossRef]

19. Hardigan, M.A.; Laimbeer, F.P.E.; Newton, L.; Crisovan, E.; Hamilton, J.P.; Vaillancourt, B.; Wiegert-Rininger, K.; Wood, J.C.; Douches, D.S.; Farré, E.M.; et al. Genome diversity of tuber-bearing solanum uncovers complex evolutionary history and targets of domestication in the cultivated potato. Proc. Natl. Acad. Sci. USA 2017, 114, E9999-E10008. [CrossRef]

20. Friedman, M. Potato glycoalkaloids and metabolites: Roles in the plant and in the diet. J. Agric. Food Chem. 2006, 54, 8655-8681. [CrossRef]

21. Moyo, L.; Ramesh, S.V.; Kappagantu, M.; Mitter, N.; Sathuvalli, V.; Pappu, H.R. The effects of potato virus Y-derived virus small interfering RNAs of three biologically distinct strains on potato (Solanum tuberosum) transcriptome. Virol. J. 2017, 14, 1-17. [CrossRef] 
22. Stare, T.; Stare, K.; Weckwerth, W.; Wienkoop, S.; Gruden, K. Comparison between proteome and transcriptome response in potato (Solanum tuberosum L.) leaves following potato virus Y (PVY) infection. Proteomes 2017, 5, 14. [CrossRef]

23. Zheng, Y.; Wang, Y.; Ding, B.; Fei, Z. Comprehensive transcriptome analyses reveal that potato spindle tuber viroid triggers genome-wide changes in alternative splicing, inducible trans-acting activity of phased secondary small interfering RNAs, and immune responses. J. Virol. 2017, 91, 1-18. [CrossRef] [PubMed]

24. Lukan, T.; Pompe-Novak, M.; Baebler, Š.; Tušek-Žnidarič, M.; Kladnik, A.; Križnik, M.; Blejec, A.; Zagorščak, M.; Stare, K.; Dušak, B.; et al. Precision transcriptomics of viral foci reveals the spatial regulation of immune-signaling genes and identifies RBOHD as an important player in the incompatible interaction between potato virus Y and potato. Plant J. 2020, 104, 645-661. [CrossRef] [PubMed]

25. Pham, G.M.; Hamilton, J.P.; Wood, J.C.; Burke, J.T.; Zhao, H.; Vaillancourt, B.; Ou, S.; Jiang, J.; Buell, C.R. Construction of a chromosome-scale long-read reference genome assembly for potato. Gigascience 2020, 9, 1-11. [CrossRef] [PubMed]

26. Scholthof, K.-B.G. Making a Virus Visible: Francis, O. Holmes and a biological assay for tobacco mosaic virus. J. Hist. Biol. 2014, 47, 107-145. [CrossRef] [PubMed]

27. Herath, V.; Verchot, J. Insight into the bzip gene family in Solanum tuberosum: Genome and transcriptome analysis to understand the roles of gene diversification in spatiotemporal gene expression and function. Int. J. Mol. Sci. 2021, 22, 253. [CrossRef]

28. Rodrigo, G.; Zwart, M.P.; Elena, S.F. Onset of virus systemic infection in plants is determined by speed of cell-to-cell movement and number of primary infection foci. J. R. Soc. Interface 2014, 11, 1-7. [CrossRef] [PubMed]

29. Carbon, S.; Douglass, E.; Dunn, N.; Good, B.; Harris, N.L.; Lewis, S.E.; Mungall, C.J.; Basu, S.; Chisholm, R.L.; Dodson, R.J.; et al. The Gene Ontology Resource: 20 years and still GOing strong. Nucleic Acids Res. 2019, 47, D330-D338. [CrossRef]

30. Rushton, P.J.; Bokowiec, M.T.; Han, S.; Zhang, H.; Brannock, J.F.; Chen, X.; Laudeman, T.W.; Timko, M.P. Tobacco transcription factors: Novel insights into transcriptional regulation in the Solanaceae. Plant Physiol. 2008, 147, 280-295. [CrossRef] [PubMed]

31. Mohanty, B.; Kitazumi, A.; Cheung, C.Y.M.; Lakshmanan, M.; de los Reyes, B.G.; Jang, I.-C.; Lee, D.-Y. Identification of candidate network hubs involved in metabolic adjustments of rice under drought stress by integrating transcriptome data and genome-scale metabolic network. Plant Sci. 2016, 242, 224-239. [CrossRef]

32. Javed, T.; Shabbir, R.; Ali, A.; Afzal, I.; Zaheer, U.; Gao, S.J. Transcription factors in plant stress responses: Challenges and potential for sugarcane improvement. Plants 2020, 9, 491. [CrossRef]

33. Tsuda, K.; Somssich, I.E. Transcriptional networks in plant immunity. New Phytol. 2015, 206, 932-947. [CrossRef]

34. Jha, P.; Kumar, V. BABY BOOM (BBM): A candidate transcription factor gene in plant biotechnology. Biotechnol. Lett. 2018. [CrossRef]

35. Herath, V. Small family, big impact: In silico analysis of DREB2 transcription factor family in rice. Comput. Biol. Chem. 2016, 65, 128-139. [CrossRef]

36. Herath, V.; Gayral, M.; Adhikari, N.; Miller, R.; Verchot, J. Genome-wide identification and characterization of Solanum tuberosum BiP genes reveal the role of the promoter architecture in BiP gene diversity. Sci. Rep. 2020, 10, 11327. [CrossRef]

37. Yun, K.Y.; Park, M.R.; Mohanty, B.; Herath, V.; Xu, F.; Mauleon, R.; Wijaya, E.; Bajic, V.B.; Bruskiewich, R.; de los Reyes, B.G. Transcriptional regulatory network triggered by oxidative signals configures the early response mechanisms of japonica rice to chilling stress. BMC Plant Biol. 2010, 10. [CrossRef] [PubMed]

38. Jindrich, K.; Degnan, B.M. The diversification of the basic leucine zipper family in eukaryotes correlates with the evolution of multicellularity Genome evolution and evolutionary systems biology. BMC Evol. Biol. 2016, 16, 1-12. [CrossRef] [PubMed]

39. Benn, G.; Wang, C.Q.; Hicks, D.R.; Stein, J.; Guthrie, C.; Dehesh, K. A key general stress response motif is regulated non-uniformly by CAMTA transcription factors. Plant J. 2014, 80, 82-92. [CrossRef] [PubMed]

40. Peng, J. Gibberellin and jasmonate crosstalk during stamen development. J. Integr. Plant Biol. 2009, 51, 1064-1070. [CrossRef] [PubMed]

41. Magyar, Z.; Bögre, L.; Ito, M. DREAMs make plant cells to cycle or to become quiescent. Curr. Opin. Plant Biol. 2016, 34, 100-106. [CrossRef]

42. Ambawat, S.; Sharma, P.; Yadav, N.R.; Yadav, R.C. MYB transcription factor genes as regulators for plant responses: An overview. Physiol. Mol. Biol. Plants 2013, 19, 307-321. [CrossRef]

43. Dubos, C.; Stracke, R.; Grotewold, E.; Weisshaar, B.; Martin, C.; Lepiniec, L. MYB transcription factors in Arabidopsis. Trends Plant Sci. 2010, 15, 573-581. [CrossRef]

44. Collinge, M.; Boller, T. Differential induction of two potato genes, Stprx2 and StNAC, in response to infection by Phytophthora infestans and to wounding. Plant Mol. Biol. 2001, 46, 521-529. [CrossRef] [PubMed]

45. Jeong, R.D.; Chandra-Shekara, A.C.; Kachroo, A.; Klessig, D.F.; Kachroo, P. HRT-mediated hypersensitive response and resistance to turnip crinkle virus in Arabidopsis does not require the function of TIP, the presumed guardee protein. Mol. Plant Microbe Interact. 2008, 21, 1316-1324. [CrossRef]

46. Carr, J.P.; Murphy, A.M.; Tungadi, T.; Yoon, J.Y. Plant defense signals: Players and pawns in plant-virus-vector interactions. Plant Sci. 2019, 279, 87-95. [CrossRef]

47. Sekhwal, M.; Li, P.; Lam, I.; Wang, X.; Cloutier, S.; You, F. Disease resistance gene analogs (RGAs) in plants. Int. J. Mol. Sci. 2015, 16, 19248-19290. [CrossRef]

48. Kourelis, J.; Kamoun, S. RefPlantNLR: A comprehensive collection of experimentally validated plant NLRs. bioRxiv 2020. [CrossRef] 
49. Lee, W.-S.; Fu, S.-F.; Verchot-Lubicz, J.; Carr, J.P. Genetic modification of alternative respiration in Nicotiana benthamiana affects basal and salicylic acid-induced resistance to potato virus X. BMC Plant Biol. 2011, 11, 41. [CrossRef] [PubMed]

50. Murphy, A.M.; Chivasa, S.; Singh, D.P.; Carr, J.P. Salicylic acid-induced resistance to viruses and other pathogens: A parting of the ways? Trends Plant Sci. 1999, 4, 155-160. [CrossRef]

51. Brugmans, B.; Wouters, D.; Van Os, H.; Hutten, R.; Van Der Linden, G.; Visser, R.G.F.; Van Eck, H.J.; Van Der Vossen, E.A.G. Genetic mapping and transcription analyses of resistance gene loci in potato using NBS profiling. Theor. Appl. Genet. 2008, 117, 1379-1388. [CrossRef]

52. Louis, B.; Rey, C. Resistance gene analogs involved in tolerant cassava-Geminivirus interaction that shows a recovery phenotype. Virus Genes 2015, 51, 393-407. [CrossRef]

53. Mushtaq, R.; Shahzad, K.; Mansoor, S.; Shah, Z.H.; Alsamadany, H.; Mujtaba, T.; Al-Zahrani, Y.; Alzahrani, H.A.S.; Ahmed, Z.; Bashir, A. Exploration of cotton leaf curl virus resistance genes and their screening in Gossypium arboreum by targeting resistance gene analogues. AoB Plants 2018, 10, 1-15. [CrossRef]

54. Gao, Y.; Xu, Z.; Jiao, F.; Yu, H.; Xiao, B.; Li, Y.; Lu, X. Cloning, structural features, and expression analysis of resistance gene analogs in tobacco. Mol. Biol. Rep. 2010, 37, 345-354. [CrossRef]

55. Osuna-Cruz, C.M.; Paytuvi-Gallart, A.; Di Donato, A.; Sundesha, V.; Andolfo, G.; Cigliano, R.A.; Sanseverino, W.; Ercolano, M.R. PRGdb 3.0: A comprehensive platform for prediction and analysis of plant disease resistance genes. Nucleic Acids Res. 2018, 46, D1197-D1201. [CrossRef]

56. Li, P.; Quan, X.; Jia, G.; Xiao, J.; Cloutier, S.; You, F.M. RGAugury: A pipeline for genome-wide prediction of resistance gene analogs (RGAs) in plants. BMC Genom. 2016, 17, 1-10. [CrossRef]

57. Ye, C.; Dickman, M.B.; Whitham, S.A.; Payton, M.; Verchot, J. The unfolded protein response is triggered by a plant viral movement protein. Plant Physiol. 2011, 156, 741-755. [CrossRef]

58. Song, Z.-T.; Sun, L.; Lu, S.-J.; Tian, Y.; Ding, Y.; Liu, J.-X. Transcription factor interaction with COMPASS-like complex regulates histone H3K4 trimethylation for specific gene expression in plants. Proc. Natl. Acad. Sci. USA 2015, 112, 2900-2905. [CrossRef]

59. Ozgur, R.; Uzilday, B.; Sekmen, A.H.; Turkan, I. The effects of induced production of reactive oxygen species in organelles on endoplasmic reticulum stress and on the unfolded protein response in arabidopsis. Ann. Bot. 2015. [CrossRef]

60. Weis, C.; Pfeilmeier, S.; Glawischnig, E.; Isono, E.; Pachl, F.; Hahne, H.; Kuster, B.; Eichmann, R.; Hückelhoven, R. Coimmunoprecipitation-based identification of putative BAX INHIBITOR-1-interacting proteins involved in cell death regulation and plant-powdery mildew interactions. Mol. Plant Pathol. 2013, 14, 791-802. [CrossRef]

61. Vitale, M.; Bakunts, A.; Orsi, A.; Lari, F.; Tadé, L.; Danieli, A.; Rato, C.; Valetti, C.; Sitia, R.; Raimondi, A.; et al. Inadequate BiP availability defines endoplasmic reticulum stress. Elife 2019, 8, 1-17. [CrossRef]

62. Dorokhov, Y.L.; Sheshukova, E.V.; Komarova, T.V. Methanol in plant life. Front. Plant Sci. 2018, 871, 1-6. [CrossRef]

63. Kogovšek, P.; Pompe-Novak, M.; Baebler, S.; Rotter, A.; Gow, L.; Gruden, K.; Foster, G.D.; Boonham, N.; Ravnikar, M. Aggressive and mild potato virus $\mathrm{Y}$ isolates trigger different specific responses in susceptible potato plants. Plant Pathol. 2010, 59, 1121-1132. [CrossRef]

64. Park, M.-R.; Jeong, R.-D.; Kim, K.-H. Understanding the intracellular trafficking and intercellular transport of potexviruses in their host plants. Front. Plant Sci. 2014, 5, 60. [CrossRef]

65. Kanneganti, V.; Gupta, A.K. Wall associated kinases from plants-An overview. Physiol. Mol. Biol. Plants 2008, 14, 109-118. [CrossRef] [PubMed]

66. Simpson, C.; Thomas, C.; Findlay, K.; Bayer, E.; Maule, A.J. An Arabidopsis GPI-anchor plasmodesmal neck protein with callose binding activity and potential to regulate cell-to-cell trafficking. Plant Cell 2009, 21, 581-594. [CrossRef] [PubMed]

67. Bernat-Silvestre, C.; Vieira, V.D.S.; Sanchez-Simarro, J.; Pastor-Cantizano, N.; Hawes, C.; Marcote, M.J.; Aniento, F. P24 Family proteins are involved in transport to the plasma membrane of gpi-anchored proteins in plants. Plant Physiol. 2020, 184, 1333-1347. [CrossRef] [PubMed]

68. Montesinos, J.C.; Langhans, M.; Sturm, S.; Hillmer, S.; Aniento, F.; Robinson, D.G.; Marcote, M.J. Putative p24 complexes in Arabidopsis contain members of the delta and beta subfamilies and. J. Exp. Bot. 2013, 64, 3147-3167. [CrossRef]

69. Chen, J.; Qi, X.; Zheng, H. Subclass-specific localization and trafficking of Arabidopsis p24 proteins in the ER-Golgi interface. Traffic 2012, 13, 400-415. [CrossRef] [PubMed]

70. Wu, K.; Zhang, X.; Sun, S.; Wang, X. Factors affecting the accumulation of curcumin in microrhizomes of Curcuma aromatica Salisb. Biomed. Res. Int. 2015, 2015, 1-10. [CrossRef]

71. Chen, Q.; Tian, Z.; Jiang, R.; Zheng, X.; Xie, C.; Liu, J. StPOTHR1, a NDR1/HIN1-like gene in Solanum tuberosum, enhances resistance against Phytophthora infestans. Biochem. Biophys. Res. Commun. 2018, 496, 1155-1161. [CrossRef]

72. Trivedi, D.K.; Ansari, M.W.; Tuteja, N. Multiple abiotic stress responsive rice cyclophilin: (OsCYP-25) mediates a wide range of cellular responses. Commun. Integr. Biol. 2013, 6. [CrossRef] [PubMed]

73. Dong, N.Q.; Sun, Y.; Guo, T.; Shi, C.L.; Zhang, Y.M.; Kan, Y.; Xiang, Y.H.; Zhang, H.; Yang, Y.B.; Li, Y.C.; et al. UDPglucosyltransferase regulates grain size and abiotic stress tolerance associated with metabolic flux redirection in rice. Nat. Commun. 2020, 11, 1-16. [CrossRef] [PubMed]

74. Mao, G.; Seebeck, T.; Schrenker, D.; Yu, O. CYP709B3, a cytochrome P450 monooxygenase gene involved in salt tolerance in Arabidopsis thaliana. BMC Plant Biol. 2013, 13, 1-13. [CrossRef] 
75. Poku, S.A.; Chukwurah, P.N.; Aung, H.H.; Nakamura, I. Over-expression of a melon Y3SK2-type LEA gene confers drought and salt tolerance in transgenic tobacco plants. Plants 2020, 9, 1749. [CrossRef]

76. Barah, P.; Naika, B.N.M.; Jayavelu, N.D.; Sowdhamini, R.; Shameer, K.; Bones, A.M. Transcriptional regulatory networks in Arabidopsis thaliana during single and combined stresses. Nucleic Acids Res. 2015, 44, 3147-3164. [CrossRef] [PubMed]

77. Xie, Z.; Nolan, T.M.; Jiang, H.; Yin, Y. AP2/ERF transcription factor regulatory networks in hormone and abiotic stress responses in Arabidopsis. Front. Plant Sci. 2019, 10, 1-17. [CrossRef]

78. Baebler, Š.; Krečič-Stres, H.; Rotter, A.; KogovŠek, P.; Cankar, K.; Kok, E.J.; Gruden, K.; KovaČ, M.; Žel, J.; Pompe-Novak, M.; et al. PVYNTN elicits a diverse gene expression response in different potato genotypes in the first $12 \mathrm{~h}$ after inoculation. Mol. Plant Pathol. 2009, 10, 263-275. [CrossRef]

79. Stare, T.; Ramšak, Ž.; Križnik, M.; Gruden, K. Multiomics analysis of tolerant interaction of potato with potato virus Y. Sci. Data 2019, 6, 1-11. [CrossRef]

80. Whitham, S.A.; Quan, S.; Chang, H.S.; Cooper, B.; Estes, B.; Zhu, T.; Wang, X.; Hou, Y.M. Diverse RNA viruses elicit the expression of common sets of genes in susceptible Arabidopsis thaliana plants. Plant J. 2003, 33, 271-283. [CrossRef]

81. Di Carli, M.; Benvenuto, E.; Donini, M. Recent insights into plant-virus interactions through proteomic analysis. J. Proteome Res. 2012, 11, 4765-4780. [CrossRef]

82. Lee, W.S.; Fu, S.F.; Li, Z.; Murphy, A.M.; Dobson, E.A.; Garland, L.; Chaluvadi, S.R.; Lewsey, M.G.; Nelson, R.S.; Carr, J.P. Salicylic acid treatment and expression of an RNA-dependent RNA polymerase 1 transgene inhibit lethal symptoms and meristem invasion during tobacco mosaic virus infection in Nicotiana benthamiana. BMC Plant Biol. 2016. [CrossRef]

83. Zhang, Y.; Pei, X.; Zhang, C.; Lu, Z.; Wang, Z.; Jia, S.; Li, W. De novo foliar transcriptome of Chenopodium amaranticolor and analysis of its gene expression during virus-induced hypersensitive response. PLoS ONE 2012, 7, 1-10. [CrossRef]

84. Allie, F.; Pierce, E.J.; Okoniewski, M.J.; Rey, C. Transcriptional analysis of South African cassava mosaic virus-infected susceptible and tolerant landraces of cassava highlights differences in resistance, basal defense and cell wall associated genes during infection. BMC Genom. 2014, 15, 1006. [CrossRef]

85. Takken, F.L.W.; Goverse, A. How to build a pathogen detector: Structural basis of NB-LRR function. Curr. Opin. Plant Biol. 2012, 15, 375-384. [CrossRef]

86. Howell, S.H. When is the unfolded protein response not the unfolded protein response? Plant Sci. 2017, 260, 139-143. [CrossRef] [PubMed]

87. Afrin, T.; Diwan, D.; Sahawneh, K.; Pajerowska-Mukhtar, K. Multilevel regulation of endoplasmic reticulum stress responses in plants: Where old roads and new paths meet. J. Exp. Bot. 2020, 71, 1659-1667. [CrossRef] [PubMed]

88. Kataoka, R.; Takahashi, M.; Suzuki, N. Coordination between bZIP28 and HSFA2 in the regulation of heat response signals in Arabidopsis. Plant Signal. Behav. 2017, 12,1-6. [CrossRef] [PubMed]

89. Zhu, F.Y.; Chen, M.X.; Ye, N.H.; Qiao, W.M.; Gao, B.; Law, W.K.; Tian, Y.; Zhang, D.; Zhang, D.; Liu, T.Y.; et al. Comparative performance of the BGISEQ-500 and Illumina HiSeq4000 sequencing platforms for transcriptome analysis in plants. Plant Methods 2018, 14, 1-14. [CrossRef] [PubMed]

90. Chen, Y.; Chen, Y.; Shi, C.; Huang, Z.; Zhang, Y.; Li, S.; Li, Y.; Ye, J.; Yu, C.; Li, Z.; et al. SOAPnuke: A MapReduce acceleration-supported software for integrated quality control and preprocessing of high-throughput sequencing data. Gigascience 2018. [CrossRef]

91. Kim, D.; Langmead, B.; Salzberg, S.L. HISAT: A fast spliced aligner with low memory requirements. Nat. Methods 2015. [CrossRef]

92. Etherington, G.J.; Ramirez-Gonzalez, R.H.; MacLean, D. Bio-samtools 2: A package for analysis and visualization of sequence and alignment data with SAMtools in Ruby. Bioinformatics 2015. [CrossRef] [PubMed]

93. Pertea, M.; Pertea, G.M.; Antonescu, C.M.; Chang, T.C.; Mendell, J.T.; Salzberg, S.L. StringTie enables improved reconstruction of a transcriptome from RNA-seq reads. Nat. Biotechnol. 2015, 33, 290-295. [CrossRef]

94. Benjamini, Y.; Hochberg, Y. Controlling the false discovery rate-A practical and powerful approach to multiple testing. J. R. Stat. Soc. B 1995, 57, 289-300. [CrossRef]

95. Haynes, W. Benjamini-Hochberg Method. In Encyclopedia of Systems Biology; Dubitzky, W., Wolkenhauer, O., Cho, K.-H., Yokota, H., Eds.; Springer: New York, NY, USA, 2013; p. 78. ISBN 978-1-4419-9863-7.

96. Chen, C.; Chen, H.; Zhang, Y.; Thomas, H.R.; Frank, M.H.; He, Y.; Xia, R. TBtools-An integrative toolkit developed for interactive analyses of big biological data. Mol. Plant 2020. [CrossRef]

97. Blum, M.; Chang, H.-Y.; Chuguransky, S.; Grego, T.; Kandasaamy, S.; Mitchell, A.; Nuka, G.; Paysan-Lafosse, T.; Qureshi, M.; Raj, S.; et al. The InterPro protein families and domains database: 20 years on. Nucleic Acids Res. 2020, 49, 1-11. [CrossRef] [PubMed]

98. Törönen, P.; Medlar, A.; Holm, L. PANNZER2: A rapid functional annotation web server. Nucleic Acids Res. 2018, 46, W84-W88. [CrossRef] [PubMed]

99. Berardini, T.Z.; Reiser, L.; Li, D.; Mezheritsky, Y.; Muller, R.; Strait, E.; Huala, E. The Arabidopsis information resource: Making and mining the "gold standard" annotated reference plant genome. Genesis 2015. [CrossRef] 